\author{
CalviNg DIFFiculties AND PERINATAL DEATH \\ IN DAUGHTER GROUPS OF BULLS OF THE $M R Y$ BREED
}

G. J. W. van det MEY, A. HELDER and S. W. J. van DIETEN

Fac. Vet. Med., Utrecht; A.I.-centre "De Kempen", Oevle, Netherlands

Birth data of daughters of $4 M R Y$ K.I.-bulls have been compared. The total number of cows was 12,875 with 28,149 births over the period from 1967 to 1974 . Only singleborn calves have been included that were born following a gestation period of 260 to 300 days. Data on abnormal birth percentage, perinatal death percentage, birth weight and gestation length are presented in tables, according to daughter group and parity of the cow ( 1,2 or $>3$ ).

Multivariate analysis showed significant differences between the daughter groups with regard to calving process, birth weight and length of the gestation period. The difference in perinatal death percentage is not significant. Significant interactions exist between calf's sire and maternal grandsire with regard to perinatal death and gestation length.

\title{
A TEST FOR CONNECTEDNESS FITTED IOR THE BLUP-PROCEDURE
}

\section{P. H. PETERSEN}

Institute of Animal Science, The Royal Veterinary

and Agricultural University, 23 Rolighedsvej, DK-I958 Copenhagen, Danemark

A test for connectedness to be performed on the half stored sire by sire submatrix after absorption of herd effects is described.

Furthermore a strategy taking advantage of a priori knowledge about a connected subset of sires is outlined. An EDP subroutine developped for the test is available by the author.

\section{A COMBINED SET OF SELECTION T'RAITS IN FVALUATING DAIRY CATTLE GENOTYPES}

\section{G. NAZARENKO}

The M.F. Ivanov Ukrainian Research Institute for Animal Husbandry in the Steppe Regions Askania Nova, U.S.S.R.

The accuracy of different procedures for dairy cattle genotype evaluation bases on such characters as milk yield, fat, protein, solid content, and body weight records has been tested in several Red Steppe Cattle populations. Rank evaluation of the cows' merit for their milk constituents revealed a high and direct dependence on the milk yield level ( $0.8 z$ to 0.94$)$, demonstrating the identical accuracy of those selection procedures. The correlated trends of the selected traits vary, as for their value, with the applying of various selection programs, and can readily be used as tests in choosing the optimum selection model.

Positive and highly significant correlations were obtained between the cows' genotype evaluation model developed by selection index approach involving heritabilities, phenotypic standard deviation, phenotypic and genetic correlations, economic value, and the individual selection traits. The rank linkage estimates in sire progeny-testing using different procedures also demonstrated the accuracy of the index method $(0.62$ to 0.83$)$.

It was established that the use of indices in sire genotype estimation, besides the differences among the groups of daughters and contemporaries, enables the consideration of the average population level, which is especially important for the ccmparability of the sire and line evaluation results in herds with different performance levels.

The selection index approach accelerates the genetic progress of a population for a combined set of economic traits under the conditions of a commercial dairy cattle breeding system. 